\title{
Nitrogen Doped Coal with High Electrocatalytic Activity for Oxygen Reduction Reaction
}

\author{
Chi Zhang, ${ }^{1}$ Yunchao Xie, ${ }^{1}$ Heng Deng, ${ }^{1}$ Cheng Zhang, ${ }^{1}$ Jhengwun Su${ }^{1}$ and Jian Lin ${ }^{1 *}$
}

It is of a great challenge to develop high efficient nonprecious electrocatalysts to replace Pt-based catalysts for oxygen reduction reaction (ORR). This study introduces a cost-effective and environmentally friendly ORR electrocatalyst based on nitrogen doped coal (NOC) via a preoxidization of raw coal followed by a urea assisted annealing process. The obtained materials show great electrocatalytic activity with the onset potential, half-wave potential, and diffusion-limited current density comparable to those of a commercial $\mathrm{Pt} / \mathrm{C}$ catalyst. In addition, it follows a four-electron pathway and has relatively low peroxide yield. Finally, it exhibits a good stability and strong tolerance to methanol poisoning. A systematic characterizations illustrate that these great performance could arise from high graphitic $\mathrm{N}$ and pyridinic $\mathrm{N}$ contents, existence of trace metal elements, and porous structures in the synthesized NOC. The demonstrated high performance makes NOC a promising catalyst for applications in metal air batteries and alkaline fuel cells.

Keywords: Coal; Nitrogen doping; Oxygen reduction reaction (ORR); Electrocatalyst

Received 23 March 2019, Accepted 11 May 2019

DOI: $10.30919 / \mathrm{es} 8 \mathrm{~d} 516$

\section{Introduction}

Oxygen reduction reaction (ORR) is a key reaction in a polymer electrolyte membrane fuel cell (PEMFC), an advanced sustainable energy conversion technology with high energy conversion efficiency and environmentally friendly features. ${ }^{1-2}$ However, as a sluggish process, the rate of the cathodic ORR is much slower than that of the anodic hydrogen oxidation reaction (HOR). Conventionally, precious metal group (PMG) based materials are used as the efficient catalysts for ORR. But high cost of the PMG severely restricts the widespread applications of PEMFC. ${ }^{3}$ Thus, it is of great importance to develop nonprecious alternatives. In the past years, doping heteroatoms (e.g., N, $\mathrm{B}, \mathrm{P}, \mathrm{F}$ and $\mathrm{S}$ ) into synthetic carbon framework has been proved as an efficient strategy. ${ }^{46}$ For instance, Zhang et al. adopted a simple annealing method to synthesize phosphorus doped graphene which showed good catalytic activity for ORR as a metal-free catalyst. ${ }^{7}$ Very recently, co-doping of nitrogen and trace amount of transition metal (e.g. Fe and $\mathrm{Co}$ ) in the form of transition metal-nitrogen-carbon (M-NC) has shown superior performance to $\mathrm{PMG}^{8.9}$

Coal, one of the most abundant carbon sources in the earth, would offer a promising potential as a starting material for producing highefficiency ORR catalysts. However, so far its main usage is still direct combustion to produce heat and electricity. By this way, the value of coal is not fully realized. Its exploration as a material for some highvalue applications such as electronics, energy storage, and catalysts has been limited. In the past decades, although coal has been explored as a carbon source to produce high-value added synthetic carbonaceous materials such as carbon nanotubes (CNTs), activated carbon (AC), and graphene, ${ }^{10-12}$ these processes all require harsh reaction conditions and

${ }^{1}$ Department of Mechanical \& Aerospace Engineering, University of Missouri, Columbia, Missouri 65211, USA

*E-mail:linjian@missouri.edu complicated experimental procedures, leading to high fabrication cost. Recently, a pioneering work was reported by Ye et al. who developed a facile one-step wet chemistry method to extract and purify graphene quantum dots from coal. ${ }^{13}$ Since then, a variety of follow-up works have been demonstrated. For instance, Keller et al. developed a solutionbased method to prepare a coal based thin film with tunable electrical properties for a Joule heating device. ${ }^{14}$ This directly utilization of coal in its pristine form has greatly broadened its applications.

Neverlethess, most of the developed processes involve a purification step, which intent to remove impurity elements such as $\mathrm{S}, \mathrm{N}, \mathrm{Fe}, \mathrm{Mn}$, $\mathrm{Al}$ and $\mathrm{Mg}$ from the coal. Though it is necessary for certain applications, it requires intensive time and results in low production yields. Moreover, it also scarifies possible benefits from these elements, as they have been proved to improve the catalytic activity of ORR. ${ }^{15}$ In the past few years, although some effort has been made to use coal as a precursor for producing electrocatalysts for $\mathrm{ORR}^{16-19}$ all of the associated synthesis methods adopted ammonia, an expensive and corrosive gas as the nitrogen source. Moreover, the utilization of the ammonia in the process is quite low. Finally, the performance of the resulting coal based electrocatalysts, some of which are even incorporated by Fe element, are still much lower than that of PMG. As a result, it is still quite imperative to develop a cost-effective and facile manner to synthesize high efficient coal based electrocatalysts. Herein, we report synthesis of nitrogen doped oxidized coal (NOC) which is synthesized by an oxidization process by strong acids. Without further purification, the oxidized coal is pyrolyzed in a nitrogen environment by using urea as the nitrogen source. The resulting materials display outstanding catalytic performance toward ORR in terms of onset potential, half-wave potential, and diffusion-limited current density, long stability, and methanol tolerance. Systematic characterizations show that the high catalytic activities could be attributed to high graphitic $\mathrm{N}$ and pyridinic $\mathrm{N}$ contents, existence of trace metal elements, and porous structures in the synthesized NOC. 


\section{Experimental details}

\subsection{Sample preparation}

Anthracite (Fisher Scientific, catalogue number S98806), $\mathrm{H}_{2} \mathrm{SO}_{4}(95-98 \%$, Sigma-Aldrich), $\mathrm{HNO}_{3}$ (70 \%, Sigma-Aldrich), and urea (SigmaAldrich) were used as received unless otherwise specified. Firstly, the coal was ball-milled for $72 \mathrm{~h}$ and then sieved with 200 mesh sieve. 0.3 $\mathrm{g}$ of the obtained fine black powder was added into a three-neck glass flask containing $60 \mathrm{~mL}$ of concentrated $\mathrm{H}_{2} \mathrm{SO}_{4}(98 \%)$ and $20 \mathrm{~m} \mathrm{~L}$ $\mathrm{HNO}_{3}(63 \%)$, and followed by sonication for $2 \mathrm{~h}$. The mixture was stirred overnight and diluted with deionized (DI) water. The obtained oxidized coal (OC) was washed and separated by centrifugation (10000 $\mathrm{rpm}, 10 \mathrm{~min}$ ) several times until the $\mathrm{pH}$ value approached 7.0. Then, OC was dried at $80{ }^{\circ} \mathrm{C}$ in an oven. $25 \mathrm{mg}$ of the dry OC was mixed with $0.5 \mathrm{~g}$ urea and grinded in an agate mortar. Finally, the mixture was pyrolyzed at $1000{ }^{\circ} \mathrm{C}$ for $60 \mathrm{~min}$ in an Argon atmosphere to produce nitrogen doped OC (NOC).

\subsection{Material characterization}

A Rigaku X-ray diffractometer (XRD) equipped with $\mathrm{Cu} \mathrm{K}-\alpha$ X-rays was used to explore the structures of the samples at a scan rate of 5 $\%$ min. A FEI Quanta 600F environmental scanning electron microscopy (SEM) equipped with Bruker Energy Dispersive X-ray spectroscopy (EDS) at a working voltage of $5 \mathrm{kV}$ was adopted to observe the surface morphology and do the elemental mapping. HRTEM was performed on a FEI Tecnai F30 Twins. X-ray photoelectron spectroscopy (XPS) measurements were performed by using a KRATOS AXIS 165 X-ray photoelectron spectrometer that is equipped with a monochromatic $\mathrm{Al}$ $\mathrm{K} \alpha$ source. Raman spectra were collected at $514 \mathrm{~nm}$ excitation using a Renishaw inVia Raman spectroscopy. Fourier transform infrared spectroscopy (FTIR) was performed using a Thermo Nicolet Avatar 360 FT-IR spectrometer (Thermo Electron Inc. USA). Nitrogen adsorption-desorption measurements were carried out with a Beckman Coulter SA 3100 Surface Area and Pore Size Analyzer.

\subsection{Electrochemical measurements}

The electrocatalytic performance of the catalysts was assessed by a CHI $708 \mathrm{E}$ electrochemical analyzer (CH Instruments, Inc.,) in a typical three-electrode setup. $4 \mathrm{mg}$ of the NOC was dispersed in a solution containing $760 \mu \mathrm{L}$ of DI water, $200 \mu \mathrm{L}$ of ethanol and $40 \mu \mathrm{L}$ of $5 \mathrm{wt} \%$ Nafion. Then the obtained ink was ultra-sonicated for 2 hours to get homogeneous dispersion. A $10 \mu \mathrm{L}$ ink was dropped on the surface of a glassy carbon rotating ring-disk electrode (RRDE, $4 \mathrm{~mm}$ in diameter) and dried in air. The RRDE deposited by ink with a mass loading of $0.31 \mathrm{mg} / \mathrm{cm}^{2}$ was used as a working electrode. A platinum wire and $\mathrm{Ag} / \mathrm{AgCl}$ served as the counter and reference electrodes, respectively. Before each measurement, the electrolyte was saturated by $\mathrm{O}_{2}$ or $\mathrm{N}_{2}$ for 30 minutes.

The electron transfer number $\mathrm{n}$ from RDE was calculated by Koutecky-Levich (K-L) equation based on the linear scan voltammetry (LSV) curves under different rotating speeds:

$$
\begin{aligned}
& \frac{1}{J}=\frac{1}{J_{L}}+\frac{1}{J_{K}}=\frac{1}{B \omega^{\frac{1}{2}}}+\frac{1}{J_{K}} \\
& \mathrm{~B}=0.62 \mathrm{nF} C_{0} D_{0}^{2 / 3} v^{-1 / 6}
\end{aligned}
$$

where $\mathrm{J}$ is the measured current density; $\mathrm{J}_{\mathrm{L}}$ and $\mathrm{J}_{\mathrm{K}}$ are the limiting current density and kinetic current density, respectively; stands for the angular rotating speed of the disk; F is Faraday constant $(96485 \mathrm{C} / \mathrm{mol})$, $\mathrm{C}_{0}$ is the bulk concentration of $\mathrm{O}_{2}$ in $0.1 \mathrm{M} \mathrm{KOH}\left(1.210^{-6} \mathrm{~mol} / \mathrm{cm}^{3}\right) ; \mathrm{D}_{0}$ is the diffusion coefficient of $\mathrm{O}_{2}$ in $0.1 \mathrm{M} \mathrm{KOH}\left(1.910^{-5} \mathrm{~cm}^{2} / \mathrm{s}\right)$; and $\mathrm{v}$ is the kinematic viscosity of $0.1 \mathrm{M} \mathrm{KOH}\left(0.01 \mathrm{~cm}^{2} / \mathrm{s}\right)$.

The peroxide yield $\left(\mathrm{H}_{2} \mathrm{O}_{2} \%\right)$ and the electron transfer number $n$
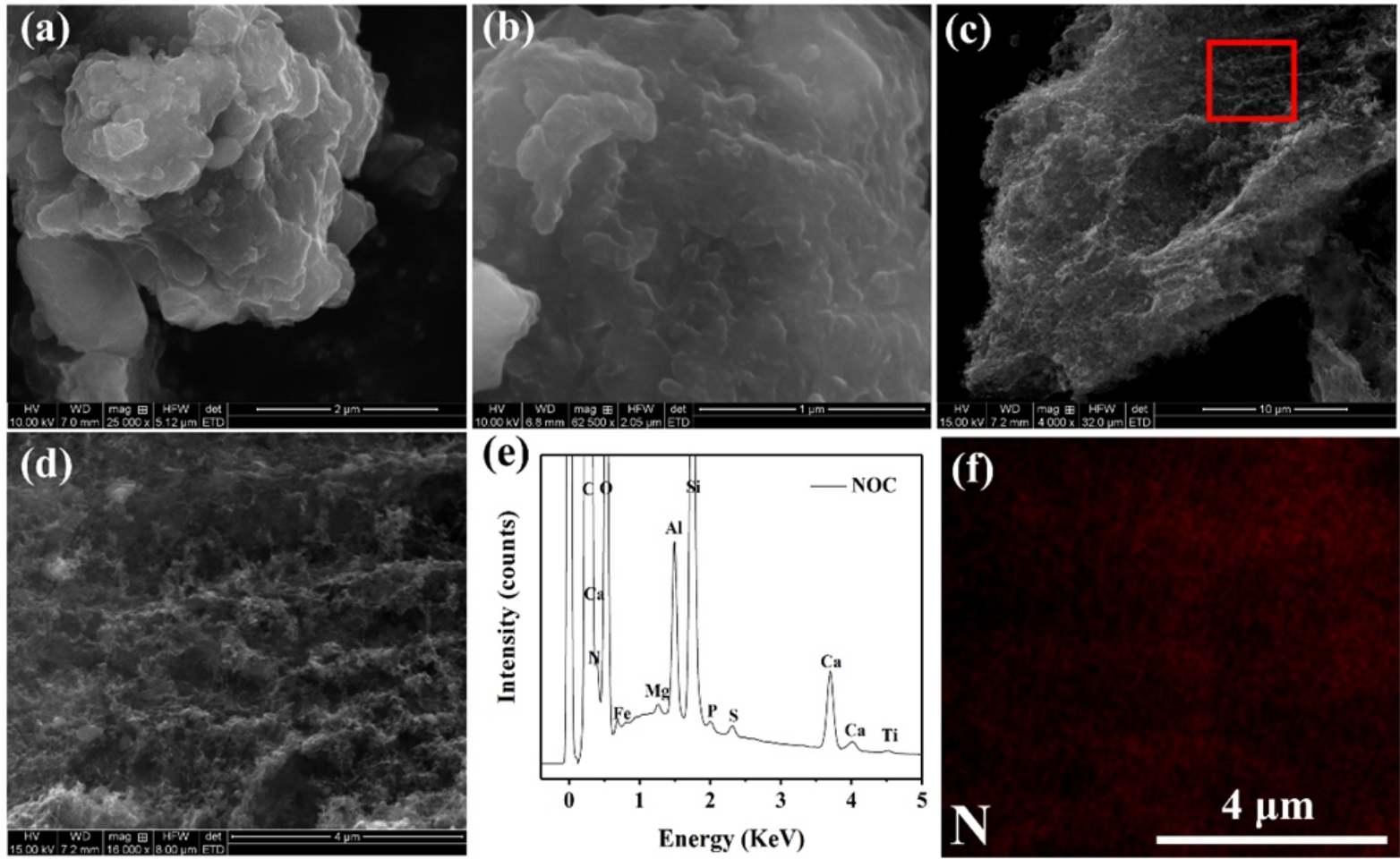

Fig. 1 (a) SEM image of raw coal. (b) SEM image of oxidized coal. (c) SEM image of nitrogen dope oxidized coal (NOC). (d) Magnified SEM image of the selected area indicated in (c). (e) EDS spectra and (f) corresponding $\mathrm{N}$ elemental mapping of the area in Fig. 1d. 
were calculated by the following equations:

$$
\begin{gathered}
\mathrm{H} O_{2}^{-}(\%)=200 \times \frac{\frac{I_{r}}{N}}{\frac{I_{r}}{N}+I_{d}} \\
\mathrm{n}=4 \times \frac{I_{d}}{\frac{I_{r}}{N}+I_{d}}
\end{gathered}
$$

where $I_{r}$ is the ring current density and $I_{d}$ is the disk current density; $N$ is the ring current collection efficiency and it is equal to 0.424 .

\section{Results and Discussion}

Surface morphology and microstructures of the raw coal (RC), OC, and the as-prepared NOC were first explored by scanning electron microscopy (SEM). As shown in Fig. 1a, after the ball milling, the raw coal exhibits an irregular surface as a bulk material. After oxidization, surface morphology of OC does not change much (Fig. 1b). After further pyrolysis, the resulting NOC exhibits highly porous microstructures (Fig. 1c-d), which can be attributed to the release of volatile matter in the coal during the high temperature thermal treatment. The energy-dispersive X-ray spectroscopy (EDS) elemental analysis was further performed on the area shown in Fig. 1d. As shown in Fig. 1e, besides the main element $\mathrm{C}$, NOC also contains $\mathrm{N}, \mathrm{O}, \mathrm{Si}$, $\mathrm{Ca}, \mathrm{Fe}, \mathrm{Mg}, \mathrm{Al}, \mathrm{Si}, \mathrm{S}$, and $\mathrm{Ti}$. It should be noted that incorporation of these elements including $\mathrm{Fe}, \mathrm{Al}, \mathrm{N}, \mathrm{Si}$ and $\mathrm{S}$ has been proved as an efficient way to boost the catalytic activity of the carbon based catalysts. ${ }^{8}$ Meanwhile, a detailed EDS spectrum corresponding to Fig. $1 \mathrm{~d}$ shows that $\mathrm{N}$ elements are uniformly distributed among the NOC matrix (Fig. 1f). High resolution transmission electron microscopy (HRTEM) was further performed to explore the structure. Fig S1 shows a typical amorphous carbon structure. The BET surface areas of the RC, NRC and NOC were also acquired by nitrogen adsorption-desorption measurements. As summarized in Table S1, NOC has a much larger surface area than NOC and RC. Such high surface area of NOC could contribute to fast mass transfer in electrocatalysis.

The raw coal and NOC were further characterized by the X-ray diffractometer (XRD). Both raw coal and NOC show a broad convoluted reflection from $20^{\circ}$ to $30^{\circ}$ corresponding to the (002) of amorphous carbon (Fig. 2a). However, the more broadening of the (002) peak in the NOC implies it has a more amorphous structure after annealing. ${ }^{17}$ In addition, both XRD patterns also illustrate very sharp and prominent peak at $26.6^{\circ}$, which arises from the $\mathrm{SiO}_{2}$ (JCPDS 11-0252), a common impurity in the coal..$^{20}$ Raman spectroscopy was used to study the structural changes of raw coal and NOC after thermal annealing (Fig. 2b). Both spectra show two prominent peaks: the D peak at $\sim 1350 \mathrm{~cm}^{-1}$ that is associated with the structural defects or bent $\mathrm{sp}^{2}$ - hybridized carbon bonds and the first-order G peak at $\sim 1590 \mathrm{~cm}^{-1}$ coming from the $\mathrm{E}_{2 \mathrm{~g}}$ stretching mode. ${ }^{21-22}$ Meanwhile, the $\mathrm{I}_{\mathrm{D}} / \mathrm{I}_{\mathrm{G}}$ increases from 0.93 to 1.15 , indicating the increase of surface defects due to oxidization or the incorporation of nitrogen into the carbon matrix, ${ }^{23}$ which is in a good agreement with the XRD results. The increase of the $\mathrm{I}_{\mathrm{D}} / \mathrm{I}_{\mathrm{G}}$ could be also attributed to the decrease of $\mathrm{sp}^{2}$ cluster size. ${ }^{14}$

XPS measurements were conducted to study chemical compositions and bonding states of RC and NOC (Fig. S2). In order to figure out influence of oxidization from strong acids on the nitrogen doping, a control sample of nitrogen doped raw coal (NRC), which was produced by directly annealing the raw coal and urea at $1000{ }^{\circ} \mathrm{C}$ for 60 min, was prepared and measured by XPS. The XPS surveys of RC, NRC and NOC (Fig. S2) show that all three samples have the same elements, suggesting that the existence of non-carbon elements even after the strong acids oxidization process. The $\mathrm{O} 1 \mathrm{~s}$ spectra of $\mathrm{RC}$, NRC, and NOC share three peaks at $530.7 \mathrm{eV}, 532.0 \mathrm{eV}$ and $533.1 \mathrm{eV}$ (Fig. S3a-c). The peak centered at $530.7 \mathrm{eV}$ can be due to existence of metal oxide. As summarized in Table S2, the relatively stable concentration of $\mathrm{O}^{2-}$ indicates the amount of trace metals is not affected by the strong acid oxidization or thermal treatment. The peaks at 532.0 $\mathrm{eV}$ and $533.1 \mathrm{eV}$ correspond to the $\mathrm{C}=\mathrm{O}$ and $\mathrm{C}-\mathrm{O}$ associated with the functional groups on the coal surface. ${ }^{24}$ Their relative concentrations are illustrated in Fig. S3d. The existence of the oxygen-functional groups is also verified by the FTIR (Fig. S4). These oxygen groups are unstable in the high temperature annealing, facilitating the nitrogen doping into the coal structures.

To prove this hypothesis, we further investigate the evolution of nitrogen contents in RC, NRC, and NOC. As indicated in the Fig. 3a, b, and $\mathrm{c}$, the $\mathrm{N}$ 1s spectra of all three samples can be deconvoluted into four different spectra, namely oxidized nitrogen at $403.4 \mathrm{eV}$, graphitic nitrogen at $401.6 \mathrm{eV}$, pyrrolic nitrogen at $400.9 \mathrm{eV}$ and pyridinic nitrogen at $398.7 \mathrm{eV}^{25}$ From them, the atomic concentrations of each type of nitrogen can be derived (Fig. 3d). The atomic concentration of total $\mathrm{N}$ in the NOC (4.06 at. \%) is almost two times of that in the NRC
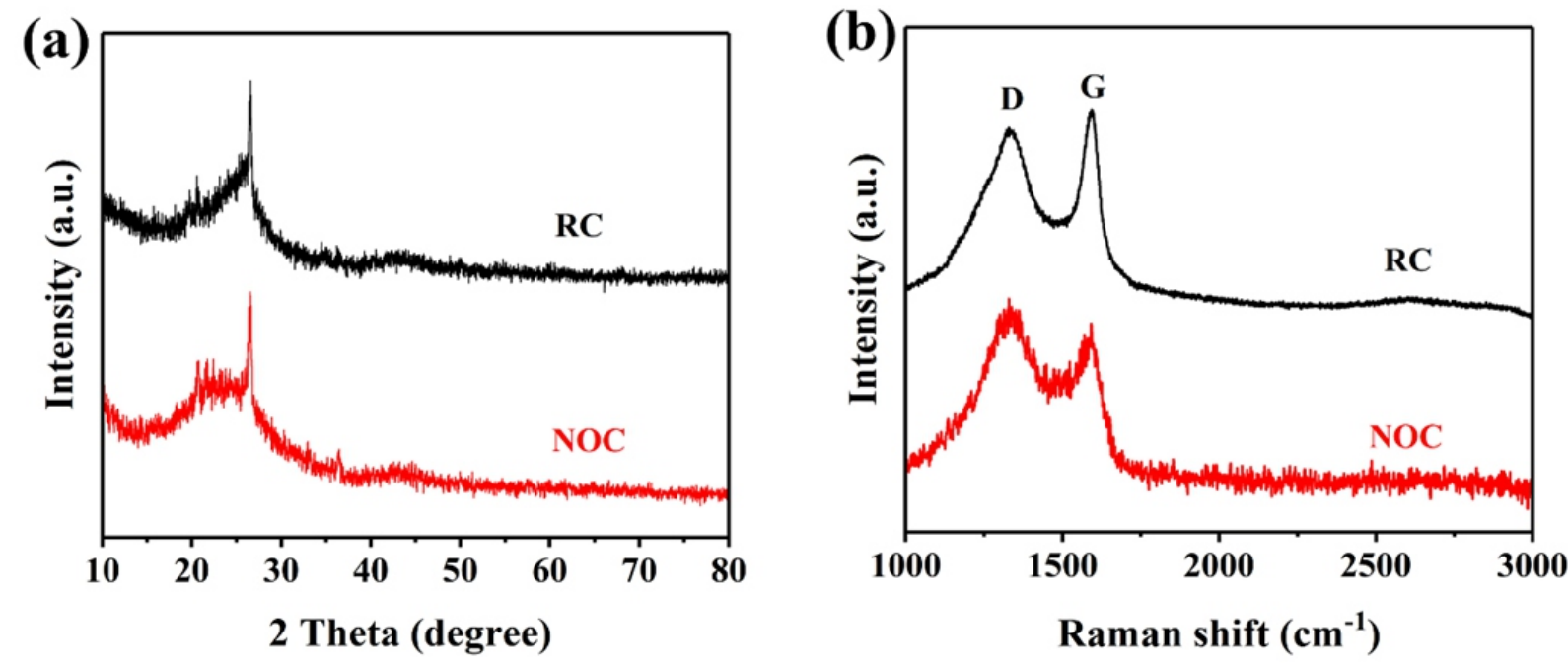

Fig. 2 (a) XRD patterns, (b) Raman spectra of raw coal and nitrogen doped oxidized coal (NOC). 
(2.22 at. \%), suggesting that the strong acid oxidization process can greatly increase the $\mathrm{N}$ doping content. A similar phenomenon has been reported by Orlando J. Rojas' group. ${ }^{26}$ They found that the $\mathrm{N}$ doping level can be increased upon acid assisted functionalization of pristine activation carbon. Meanwhile, the relative concentrations of different types of nitrogen contributions in the total nitrogen contents for $\mathrm{RC}$, NRC, and NOC are summarized in Table S2. The relative concentration of pyrrolic $\mathrm{N}$ in NRC is $21.02 \%$, which is very close to that of RC $(23.09 \%)$. Whereas with the oxidization, the relative concentration of pyrrolic $\mathrm{N}$ in the NOC is greatly decreased to $12.71 \%$, while the pyridinic $\mathrm{N}$ and graphitic $\mathrm{N}$ increase to $33.68 \%$ and $37.96 \%$, respectively. Recent experiment illustrated that the pyridinic $\mathrm{N}$ is the main contributor to enhance the ORR activity in the carbon based materials. $^{27}$

Electrocatalytic activity of the NOC was first assessed by the cyclic voltammetry $(\mathrm{CV})$ in $\mathrm{O}_{2}$-saturated or $\mathrm{N}_{2}$-saturated alkaline solutions. As shown in the Fig. 4a, there is a prominent cathodic peak corresponding to $\mathrm{O}_{2} / \mathrm{OH}$ - in an $\mathrm{O}_{2}$ saturated electrolyte within the potentials ranging from -0.05 to $1.5 \mathrm{~V}$. This reduction peak vanished in the $\mathrm{N}_{2}$-saturated electrolyte, indicating a high ORR activity of NOC. ${ }^{28}$ Linear sweep voltammetry (LSV) measurement was further conducted to assess the activity of NOC at a scan rate of $10 \mathrm{mV} / \mathrm{s}$ (Fig. 4b). As a comparison, $\mathrm{RC}, \mathrm{NRC}$, and commercial $20 \mathrm{wt} \% \mathrm{Pt} / \mathrm{C}$ were evaluated under the same condition. Common descriptors for evaluating electrocatalysts toward ORR are the onset potential $\left(\mathrm{E}_{\text {onset }}\right)$ and halfwave potential $\left(\mathrm{E}_{1 / 2}\right)$. The onset potential is defined as the potential corresponding to a current density of $-0.1 \mathrm{~mA} / \mathrm{cm}^{2}{ }^{29}$ A higher $E_{\text {onset }}$ suggests a higher catalytic activity. $\mathrm{E}_{\text {onset }}$ of $\mathrm{RC}$ is $\sim 0.752 \mathrm{~V}$ and it increases a little after directly nitrogen doping without oxidization.
Whereas, NOC has a much more positive $\mathrm{E}_{\text {onset }}$ of $0.945 \mathrm{~V}$, which is very close to that of $\mathrm{Pt} / \mathrm{C}(0.966 \mathrm{~V})$. NOC shows a high $\mathrm{E}_{1 / 2}$ which corresponds to the potential at which half of the peak current is observed of $0.755 \mathrm{~V}$. It is slightly smaller than that of the $\mathrm{Pt} / \mathrm{C}(0.831$ V), further verifying its superior activity. It also indicates that introduction of the peroxidation step can significantly improve the ORR activity. The high ORR activity of NOC is also reflected on its high diffusion-limited current density of $5.1 \mathrm{~mA} / \mathrm{cm}^{2}$ at $0.2 \mathrm{~V}$ (vs. RHE). It is almost the same to that of $5.2 \mathrm{~mA} / \mathrm{cm}^{2}$ for $\mathrm{Pt} / \mathrm{C}$ and superior to many of the reported nonprecious catalysts. ${ }^{17,30-31}$ Fig. $4 \mathrm{c}$ reveals a small Tafel slope of $90 \mathrm{mV} / \mathrm{dec}$ delivered by the NOC, suggesting its good kinetic activity.

The electron transfer kinetics and the pathway of ORR can be further clarified by evaluating the electron transfer number (n) per $\mathrm{O}_{2}$ molecule and the yield of peroxide molecule $\left(\mathrm{H}_{2} \mathrm{O}_{2} \%\right)$ (Fig. 4d). The measured $\mathrm{n}$ of $\mathrm{NOC}$ at $0.7 \mathrm{~V}$ is 3.77 , implying that it follows a fourelectron pathway in a potential range of $0.6 \mathrm{~V}$ to $0.8 \mathrm{~V}^{32}$ The LSV curves of NOC at different rotating speeds $(225 \sim 1600 \mathrm{rpm})$ are plotted in the Fig. 4e. As expected, the $\mathrm{E}_{\text {onset }}$ remains constant, while the cathodic current density increases with the increase of the rotation speeds, which is due to the enhanced mass transport. Fig. $4 \mathrm{f}$ is the corresponding Koutecky-Lecich (K-L) plot under different applied potentials. The good linearity of the K-L plot indicates the first-order reaction kinetics. ${ }^{28}$ The fitted lines measured under different potentials are almost parallel, suggesting consistent $n$ values. ${ }^{33}$ The calculated $n$ is 3.7 agrees well with the result shown in Fig. $4 d$, further demonstrating the four-electron pathway.

The outstanding electrochemical activity of the NOC can be mainly attributed to the following reasons. First of all, as shown in
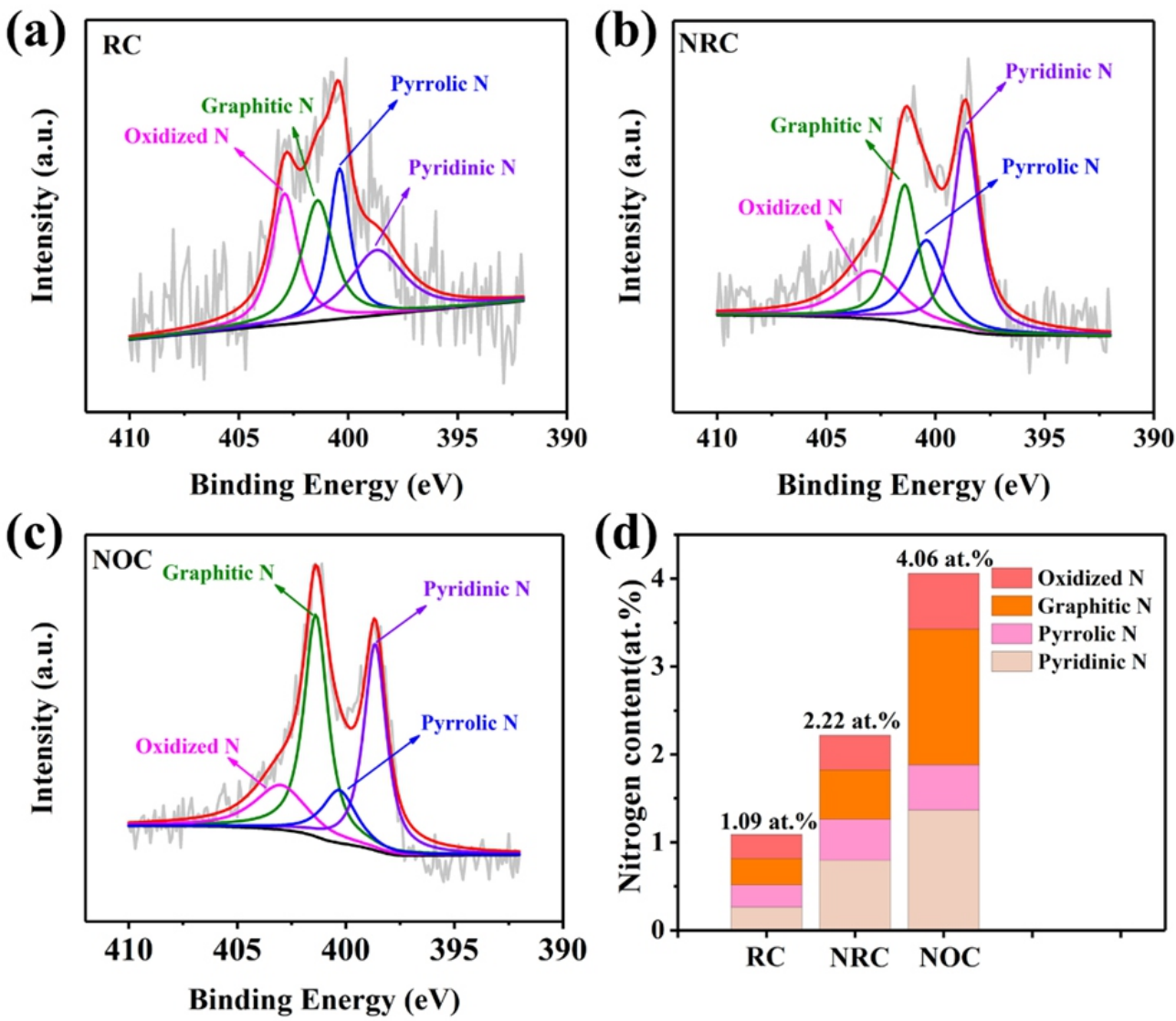

Fig. 3 XP N 1s spectra of (a) RC, (b) NRC, and (c) NOC. (d) The atomic content of nitrogen in RC, NRC and NOC. 
(a)

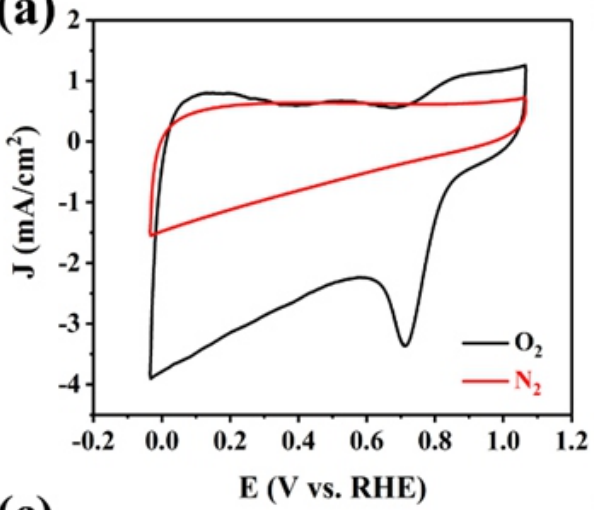

(c)
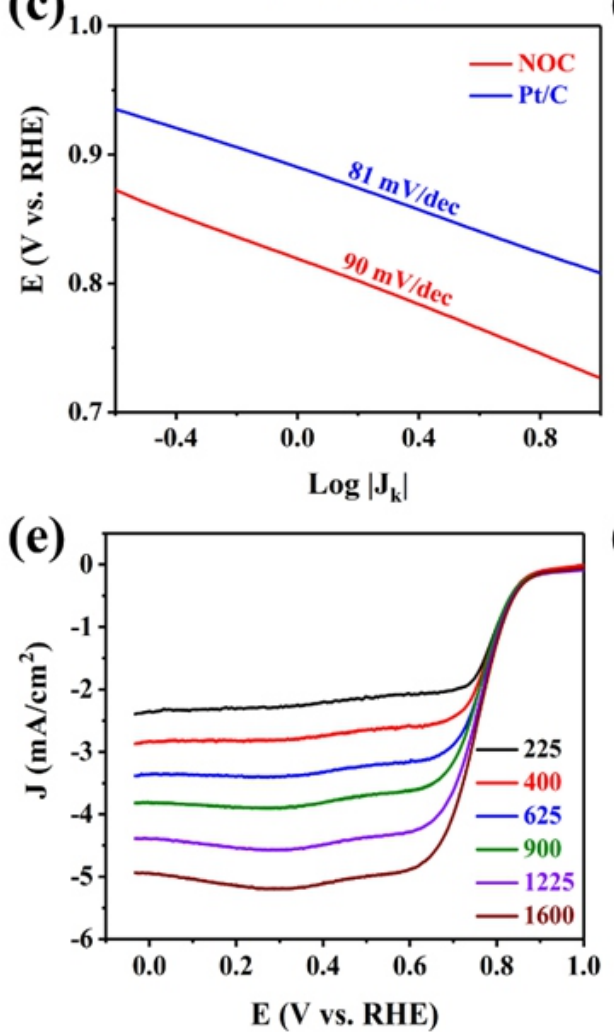

(b)

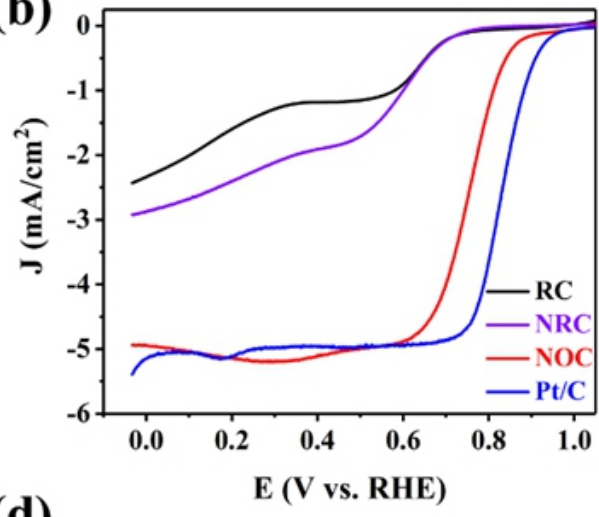

(d)

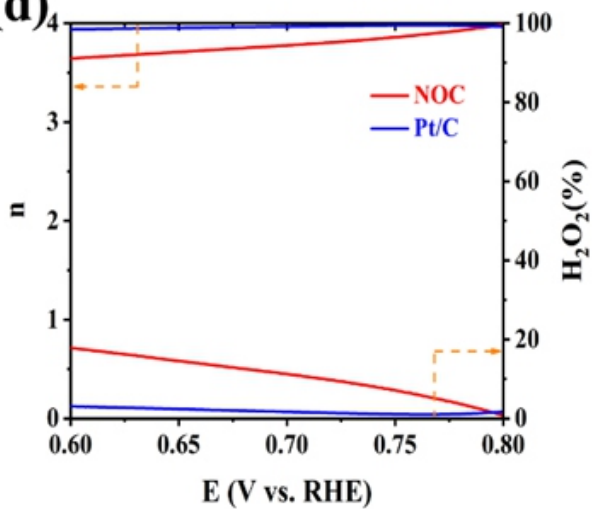

(f)

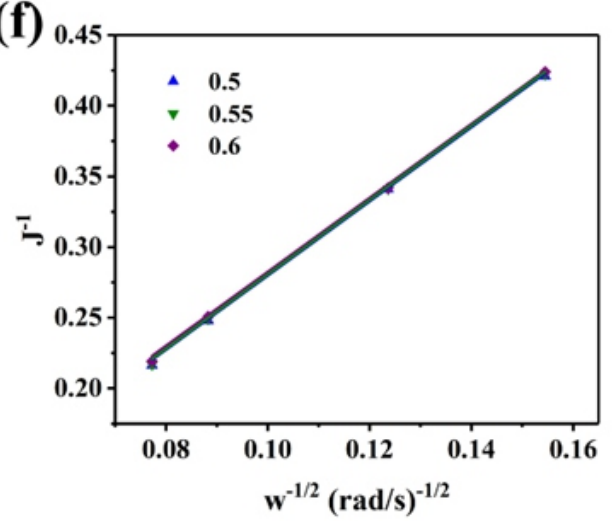

Fig. 4 (a) Cyclic voltammetry curves of $\mathrm{NOC}$ in $\mathrm{O}_{2}$-saturated or $\mathrm{N}_{2}$-saturated $0.1 \mathrm{M} \mathrm{KOH}$ electrolytes. (b) Linear sweep voltammetry (LSV) curves of $\mathrm{RC}, \mathrm{NRC}, \mathrm{NOC}$ and Pt/C at $1600 \mathrm{rpm}$. (c) Tafel slope (d) electron transfer number (n) and $\mathrm{H}_{2} \mathrm{O}_{2}$ yield of NOC and Pt/C. (e) LSV curves, and (f) Koutecky-Levich plots of NOC at different rotation speeds.
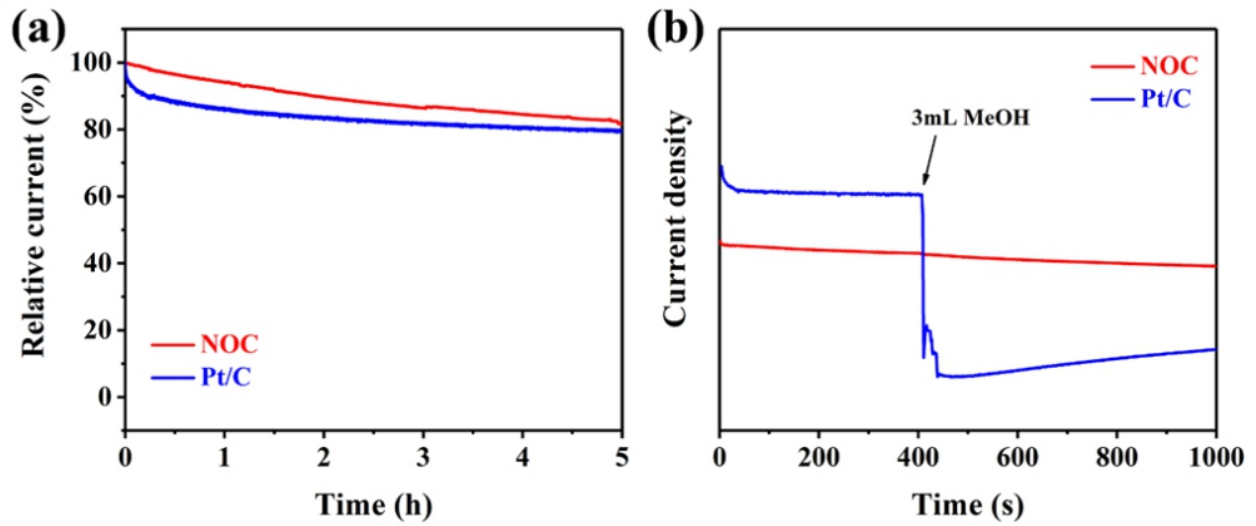

Fig. 5 (a) Chronoamperometry curves of $\mathrm{NOC}$ and $\mathrm{Pt} / \mathrm{C}$ at $0.7 \mathrm{~V}$ at $900 \mathrm{rpm}$ in $\mathrm{O}_{2}$-saturated $0.1 \mathrm{M} \mathrm{KOH}$ electrolyte. (b) Chronoamperometry curves of $\mathrm{NOC}$ and $\mathrm{Pt} / \mathrm{C}$ before and after adding $3 \mathrm{~mL}$ of methanol at about $400 \mathrm{~s}$. 
Table S2, the NOC has relatively high concentrations of graphitic N $(37.96 \%)$ and pyridinic N (33.68\%). Although the exact contribution of nitrogen dopants to the ORR is still under debate, it has reached a broad consensus that both graphitic $\mathrm{N}$ and pyridinic $\mathrm{N}$ are beneficial for enhancing ORR catalytic activity instead of oxidized $\mathrm{N}$ and pyrrolic $\mathrm{N}^{34}$ Graphitic $\mathrm{N}$ can affect electronic structures of carbon by introducing extra electrons in the delocalized $\pi$-system. ${ }^{9}$ Recently, Junji Nakamura's group experimentally proved that pyridinic $\mathrm{N}$ is responsible for creation of the active sites in nitrogen doped highly oriented pyrolytic graphite (HOPG) ${ }^{27}$ Meanwhile, the main reaction mechanism of NOC is derived based on their proposed theory for nitrogen doped carbon materials. To be specific, the oxygen molecule is firstly absorbed by the active site (carbon atoms next to pyridinic N), then gets one proton. Since NOC follows a four-electron pathway, two more protons would attach the protonated oxygen molecule, resulting in the breakage of the $\mathrm{O}-\mathrm{OH}$ bond and formation of one water molecule. Then one more proton would react with the left $\mathrm{OH}$ to form another $\mathrm{H}_{2} \mathrm{O}$ and desorb (Fig. S5). Second, the existence of trace amount of metal elements (e.g. Fe, Al) plays an important role in improving the ORR activity of NOC. In the past five years, more and more researchers unveil that trace metal impurities can significantly promote the ORR activity. ${ }^{35-36}$ For example, very recently Tour's group found that graphene oxide synthesized by the improved Hummer method contains trace metal impurities, manganese residues. ${ }^{15}$ They proved that those $\mathrm{Mn}$ especially Mn mononuclear-centered structure contribute to the catalytic activity. Since NOC have impurities as shown in the Fig. 1e and high nitrogen doping content, it is reasonable to hypothesize that the metal impurities could possibly form Metal-Nitrogen-Carbon structure which has been widely demonstrated as active sites for ORR ${ }^{37}$ Meanwhile, the nonmetal impurities could modulate the electronic structure. ${ }^{38}$ As a result, impurities in the coal also promote the electrocatalytic activity of NOC. Third, as revealed by the SEM (Fig. 1d) and BET (Table S1), the porous structures of the NOC with high surface area can enhance the accessibility of the oxygen molecules to the active sites and benefit the kinetic process.

Besides, long term stability and methanol tolerance were evaluated by Chronoamperometry measurement. Fig. 5a shows that the NOC can maintain its $\sim 82 \%$ of its original performance after $5 \mathrm{~h}$, which can be attributed to the strong $\mathrm{C}-\mathrm{N}$ covalent bonding. ${ }^{39}$ Fig. $5 \mathrm{~b}$ shows that Chronoamperometry curves before and after adding $3 \mathrm{~mL}$ of methanol. As expected, there is a significantly current density drop for the $\mathrm{Pt} / \mathrm{C}$ due to the methanol oxidation reaction. While, there is no obvious change for the NOC, suggesting its good poison tolerance toward methanol. The good stability and strong tolerance to methanol poisoning make the NOC a promising candidate for a replacement of commercial $\mathrm{Pt} / \mathrm{C}$.

\section{Conclusion}

In summary, this work presents a cost-effective and environmentally friendly method to synthesize an ORR electrocatalyst by using an earthabundant coal as the precursor. The obtained NOC shows an outstanding catalytic activity, long-term stability, and good tolerance toward methanol poisoning, all of which are comparable to that of the commercial $\mathrm{Pt} / \mathrm{C}$ catalyst. Such good performance can be ascribed to (1) high concentrations of graphitic N and pyridinic N; (2) the existence of trace metal elements; (3) porous structures with high surface area. The method shows a great route to upgrade the coal for high-value applications, laying solid foundation for applications in supercapacitor, electrochemical sensor, and gas (e.g. $\mathrm{CO}_{2}$ ) absorption.

\section{Acknowledgements}

This work was supported by the NASA Missouri Space Consortium (00049784), NASA Goddard Space Flight Ctr. (00057234), United States Department of Agriculture (2018-67017-27880), Department of Energy National Energy Technology Laboratory (Award Number: DEFE0031645), and MU's Electron Microscopy Core "Excellence in Electron Microscopy Award".

\section{References}

1. M. K. Debe, Nature, 2012, 486 (7401), 43.

2. M. Winter and R. J. Brodd, Chem. Rev., 2004, 104 (10), 4245-4270.

3. A. Morozan, B. Jousselme and S. Palacin, Energy Environ. Sci. 2011, 4 (4), 1238-1254.

4. H. Fei, R. Ye, G. Ye, Y. Gong, Z. Peng, X. Fan, E. L. Samuel, P. M. Ajayan and J. M. Tour, ACS Nano, 2014, 8 (10), 10837-10843.

5. Z. W. Liu, F. Peng, H. J. Wang, H. Yu, W. X. Zheng and J. Yang, Angew. Chem. Int. Ed. 2011, 50 (14), 3257-3261.

6. M. Borghei, P. Kanninen, M. Lundahl, T. Susi, J. Sainio, I. Anoshkin, A. Nasibulin, T. Kallio, K. Tammeveski, E. Kauppinen and V. Ruiz, Appl. Catal. $B, 2014, \mathbf{1 5 8 - 1 5 9}, 233-241$.

7. C. Zhang, N. Mahmood, H. Yin, F. Liu and Y. Hou, Adv. Mater, 2013, 25 (35), $4932-4937$.

8. M. M. Hossen, K. Artyushkova, P. Atanassov and A. Serov, J. Power. Sources., 2018, 375, 214-221.

9. Y. Nie, Y. Li and Z. Wei, Chem. Soc. Rev., 2015, 44 (8), 2168-2201.

10. K. Moothi, S. E. Iyuke, M. Meyyappan and R. Falcon, Carbon, 2012, 50 (8), 2679-2690.

11. H. Teng, T. S. Yeh and L.Y. Hsu, Carbon, 1998, 36 (9), 1387-1395.

12. S. P. Sasikala, L. Henry, G. Yesilbag Tonga, K. Huang, R. Das, B. Giroire, S. Marre, V. M. Rotello, A. Penicaud and P. Poulin, ACS Nano, 2016, 10 (5), 5293-5303.

13. R. Ye, C. Xiang, J. Lin, Z. Peng, K. Huang, Z. Yan, N. P. Cook, E. L. Samuel, C. C. Hwang and G. Ruan, Nat. Commun., 2013, 4, 2943.

14. B. D. Keller, N. Ferralis and J. C. Grossman, Nano Lett., 2016, 16 (5), 29512957.

15. R. Ye, J. Dong, L. Wang, R. Mendoza Cruz, Y. Li, P. F. An, M. J. Yacamán, B. I. Yakobson, D. Chen and J. M. Tour, Carbon, 2018, 132, 623-631.

16. X. Chen, J. Wang, X. Huang, X. Zhao, P. Liu, B. He, T. Wang and J. Masa, Catal. Sci. Technol., 2018, 8 (4), 1104-1112.

17. X. Chen, X. Huang, T. Wang, S. Barwe, K. Xie, Y. U. Kayran, D. Wintrich, W. Schuhmann and J. Masa, Electrochim. Acta, 2016, 211, 568-575.

18. S. M. Shamsunnahar and M. Nagai, Fuel, 2014, 126, 134-142.

19. M. Muraoka, H. Tomonaga and M. Nagai, Fuel, 2012, 97, 211-218.

20. H. Zhao, L. Wang, D. Jia, W. Xia, J. Li and Z. Guo, J. Mater. Chem. A, 2014, 2 (24), 9338-9344.

21. J. Lin, Z. Peng, Y. Liu, F. Ruiz-Zepeda, R. Ye, E. L. Samuel, M. J. Yacaman, B. I. Yakobson and J. M. Tour, Nat. Commun., 2014, 5, 5714.

22. H. Deng, C. Zhang, Y. Xie, T. Tumlin, L. Giri, S. P. Karna and J. Lin, J. Mater. Chem. A, 2016, 4 (18), 6824-6830.

23. Z. Wang, P. Li, Y. Chen, J. Liu, H. Tian, J. Zhou, W. Zhang and Y. Li, J. Mater. Chem. C, 2014, 2 (35), 7396-7401.

24. N. Komba, Q. Wei, G. Zhang, F. Rosei and S. Sun, Appl. Catal. B, 2019, 243, 373-380.

25. Y. Dong, M. T. Gahl, C. Zhang and J. Lin, Nanotechnology, 2017, 28 (50), 505602 .

26. M.Borghei, N. Laocharoen, E. Kibena-Põldsepp, L. S. Johansson, J. Campbell, E. Kauppinen, O. J. Porous N Tammeveski and O. J. Rojas, Appl. Catal. B, 2017, 204, 394-402.

27. D. Guo, R. Shibuya, C. Akiba, S. Saji, T. Kondo and J. Nakamura, Science, 2016, 351 (6271), 361-365.

28. H. Yu, A. Fisher, D. Cheng and D. Cu Cao, Acs. Appl. Mater. Inter, 2016, 8 (33), 21431-21439.

29. R. Sibul, E. Kibena-Põldsepp, S. Ratso, M. Kook, M. Käärik, M. Merisalu, P. Paiste, J. Leis, V. Sammelselg, K. Tammeveski, Electrochem. Commun., 2018, 93, 39-43. 
30. M. Ren, J. Zhang and J. M. Tour, Carbon, 2018, 139, 880-887.

31. R. Ye, Z. Peng, T. Wang, Y. Xu, J. Zhang, Y. Li, L. G. Nilewski, J. Lin and J. M. Tour, ACS Nano, 2015, 9 (9), 9244-9251.

32. Y. Xie, C. Zhang, X. He, J. W. Su, T. Parker, T. White, M. Griep and J. Lin, Appl. Surf. Sci., 2019, 464, 344-350.

33. P. Yin, T. Yao, Y. Wu, L. Zheng, Y. Lin, W. Liu, H. Ju, J. Zhu, X. Hong and Z. Deng, Angew. Chem. Int. Ed., 2016, 55 (36), 10800-10805.

34. L. Lai, J. R. Potts, D. Zhan, L. Wang, C. K. Poh, C. Tang, H. Gong, Z. Shen, J. Lin and R. S. Ruoff, Energy Environ. Sci., 2012, 5 (7), 7936-7942.

35. L. Wang, A. Ambrosi and M. Pumera, Angew. Chem., 2013, 125 (51), 14063-14066.
36. J. Masa, W. Xia, M. Muhler and W. Schuhmann, Angew. Chem. Int. Ed., 2015, 54 (35), 10102-10120

37. H. Zhang, S. Hwang, M. Wang, Z. Feng, S. Karakalos, L. Luo, Z. Qiao, X. Xie, C. Wang and D. Su, J. Am. Chem. Soc., 2017, 139 (40), 14143-14149.

38. X. X. Chen, J.Wang, X. N. Huang, X. F. Zhao, P. G. Liu, B. C. He, T. Wang and J. Masa, Catal. Sci. Technol., 2018, 8 (4), 1104-1112.

39. J. Wu, Z. Yang, X. Li, Q. Sun, C. Jin, P. Strasser and R. Yang, J. Mater. Chem. A, 2013, 1 (34), 9889-9896.

Publisher's Note Engineered Science Publisher remains neutral with regard to jurisdictional claims in published maps and institutional affiliations. 